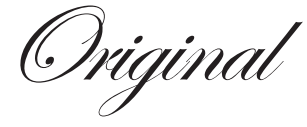

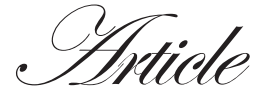

\section{Fibrosis in non-alcoholic fatty liver disease: correlation with simple blood indices and association with tumor necrosis factor-alpha polymorphisms.}

\author{
Sudipta Dhar Chowdhury ${ }^{1}$, Banumathi Ramakrishna ${ }^{2}$, Chundamannil \\ Eapen Eapen ${ }^{1}$, Ashish Goel ${ }^{1}$, Uday George Zachariah ${ }^{1}$, Anuradha \\ Chandramohan ${ }^{3}$, Srinivasan Pugazendhi ${ }^{1}$, Balakrishnan Siddartha \\ Ramakrishna $^{1}$, George Kurian ${ }^{1}$.
}

\section{ABSTRACT}

Departments of Gastrointestinal Sciences ${ }^{1}$, Pathology ${ }^{2}$ and Radiology ${ }^{3}$, Christian Medical College, Vellore 632004. India

Correspondence:

Dr. Banumathi Ramakrishna

Email: $\underline{\text { banu@cmcvellore.ac.in }}$
Aim: The study was conducted with an aim to evaluate the clinico-pathological profile, the correlation of AST: ALT ratio and APRI with histological fibrosis, and the frequency of two specific polymorphisms $(-238,-308)$ in the TNF alpha promoter region in patients with NAFLD. Methods: The present study compared aspartate transaminase/alanine transaminase (AST/ ALT) ratio and AST-to-platelet ratio index (APRI) with fibrosis score in 29 patients who underwent liver biopsy for NAFLD. Single nucleotide polymorphisms (SNP) in the tumor necrosis factor-alpha (TNF- $\alpha$ ) promoter region at positions -308 and -238 were examined by polymerase chain reaction-restriction fragment length polymorphism.

Results: AST/ALT ratio correlated better than the APRI with liver fibrosis in patients with NAFLD (AUROC of 0.9 compared to 0.68 ). TNF- $\alpha$ promoter region SNPs were present in only a minority of patients, and did not correlate with fibrosis severity.

Conclusions: AST/ALT ratio correlated well with liver fibrosis in Indian patients with NAFLD. The SNPs studied had no role in development of fibrosis in Indian patients with NAFLD.

KEYWORDS: Non alcoholic fatty liver disease (NAFLD), AST/ALT ratio, APRI, Fibrosis

\section{Introduction}

Non-alcoholic fatty liver disease (NAFLD) is a spectrum that includes simple steatosis, non-alcoholic steatohepatitis (NASH) and cirrhosis. ${ }^{1}$ Identification of the latter usually requires evaluation of liver stiffness by special probes or the gold standard, liver biopsy. Liver biopsy remains the gold standard test for grading and staging of the disease. ${ }^{2}$ The invasive nature and the associated risks have prompted researchers to develop alternative non-invasive markers of liver fibrosis. ${ }^{2}$ The AST/ALT (aspartate transaminase/alanine transaminase) ratio and AST-to-platelet ratio index (APRI) are two such non-invasive tests obtained from simple laboratory parameters. ${ }^{3,4}$
Not all individuals with NAFLD will progress to fibrosis. A 'second hit' on a baseline of steatosis is required to produce inflammation and fibrosis. ${ }^{5}$ Cytokine interaction with oxidative stress and lipid peroxidation appears to be a key mediator of the second hit. ${ }^{5}$ Increased serum levels of tumor necrosis factor alpha (TNF- $\alpha$ ) have been reported in patients with NASH ${ }^{6}$ and it has been implicated as one of the cytokines involved in the pathogenesis of NAFLD. ${ }^{7}$ Production rates of TNF- $\alpha$ vary amongst individuals and this may be related to genetic variation within the TNF- $\alpha$ locus. ${ }^{8}$ Polymorphisms in the TNF$\alpha$ promoter region one at position -308 (called TNF2 allele) ${ }^{9}$ and another at position -238 (TNFA allele) ${ }^{10}$ have been

(C) Tropical Gastroenterology 2013 
identified. TNF2 allele leads to increased constitutive and inducible expression of TNF- $\alpha$ compared to the wild type (TNF1) ${ }^{9}{ }^{911}$ Conflicting data have been reported with TNF A allele. ${ }^{12}$ Valenti et al have reported a high frequency of -238 allele in Italian patients with NAFLD. ${ }^{13}$

The study was conducted with an aim to evaluate the clinico-pathological profile, the correlation of AST:ALT ratio and APRI with histological fibrosis, and the frequency of two specific polymorphisms $(-238,-308)$ in the TNF- $\alpha$ promoter region in patients with NAFLD.

\section{Methods}

During the period February 2008 to February 2010, a prospective study was conducted at the Departments of Gastroenterology and Pathology at the Christian Medical College, Vellore. Consecutive patients with NAFLD who underwent liver biopsy and consented for inclusion in this study were included. Patients with alternative etiology for steatosis/hepatitis were excluded, (i.e., history of significant ethanol use (more than $140 \mathrm{~g} /$ week in men, or $70 \mathrm{~g} /$ week in women $)^{14}$ viral hepatitis (hepatitis B/C), Wilson's disease, autoimmune hepatitis, and exposure to drugs known to cause hepatic steatosis. All the individuals were interviewed using a standard questionnaire including symptoms, presence of risk factors for fatty liver disease, alcohol use and drug intake. Anthropometric measures (body mass index (BMI kg/m²) and waist circumference (WC) were calculated for all patients. Overweight and obesity were defined as per the criteria for Asians as a BMI of $\geq 23 \mathrm{~kg} / \mathrm{m}^{2}$ and $\geq 25 \mathrm{~kg} / \mathrm{m}^{2}$ respectively. ${ }^{15}$ Central obesity was defined as a waist circumference of $\geq 90 \mathrm{~cm}$ in men and $\geq 80 \mathrm{~cm}$ in women. ${ }^{16}$ Hypertension was defined as a systolic blood pressure of $\geq$ $140 \mathrm{mmHg}$ or diastolic $\geq 90 \mathrm{mmHg} \cdot{ }^{17} \mathrm{~A}$ fasting plasma glucose of $\geq 126 \mathrm{mg} / \mathrm{dL}, 2$ hour post-prandial plasma glucose $>200 \mathrm{mg} /$ $\mathrm{dL}$ or $\mathrm{HbA}_{1} \mathrm{C}>6.5 \%$ was used to diagnose diabetes mellitus. ${ }^{18}$ Dyslipidemia was defined as triglycerides $>150 \mathrm{mg} / \mathrm{dL}$, HDL cholesterol $<40 \mathrm{mg} / \mathrm{dL}$ in men and $<50 \mathrm{mg}$ in women. ${ }^{19}$ Liver biopsy was performed in all patients. Histological features were graded using the scoring system devised by Kleiner et al. ${ }^{20}$ Fibrosis was graded as 0 - no fibrosis, 1 - perisinusoidal or periportal fibrosis, 2 - perisinusoidal and portal / periportal, 3 bridging fibrosis, 4 - cirrhosis. Significant fibrosis was defined as fibrosis grade $\geq 2 .{ }^{21}$ The correlation of AST/ALT ratio and APRI, with the presence of significant fibrosis was tested. APRI was calculated using the formula as per Wai et al:(Patient AST / AST (upper limit of normal ) / Platelet count $\left(10^{9} / \mathrm{L}\right)$ x $100 .{ }^{22} \mathrm{~A}$ sample of blood in a $9.0 \mathrm{ml}$ EDTA tube was obtained from patients for genetic tests. Genomic DNA was extracted from EDTA-preserved peripheral venous blood using QiAmp kits. Screening for polymorphisms in the TNF $\alpha$ promoter region was performed by polymerase chain reaction-restriction fragment length polymorphism (PCR-RFLP) as described by Gordon et al. ${ }^{23}$

Data was analysed using SPSS version 17 and presented as median with range. Receiver operating characteristic (ROC) curve was used to assess the diagnostic accuracy of the noninvasive tests and area under the ROC (AUROC) was used to compare the accuracy of the tests. The study was funded by the Institutional research board and approved by the institutional ethics committee of Christian Medical College, Vellore, India.

\section{Results}

Twenty-nine consecutive patients were included in the study. Baseline demography is given in Table 1. Six patients were detected with fatty liver disease on biopsy while they were being investigated for chronic liver disease.Two patients were referred for evaluation after they were incidentally detected with fatty liver prior to planned organ donation. The rest were

Table: 1. Baseline parameters in 29 consecutive patients with biopsy proven NAFLD.

\begin{tabular}{lc}
\hline Baseline parameters & \\
\hline $\begin{array}{l}\text { Age (median (range)) } \\
\text { Sex M:F }\end{array}$ & $43(30-60)$ years \\
Anthropometry & $22: 7$ \\
\hline $\begin{array}{l}\text { - Body mass index (BMI) }-\mathrm{Kg} / \mathrm{m}^{2} \\
\quad(\text { median (range) }\end{array}$ & $25.1(19.7-30.1)$ \\
- $\quad \begin{array}{l}\text { Waist circumference }(\mathrm{cms}) \\
\quad(\text { median (range) }\end{array}$ & $95.25(63-110)$
\end{tabular}

\section{Laboratory}

- AST (median (range)) $57(16-169)$ IU

- ALT (median (range)) $74(15$ - 192) IU

- Platelet (median (range)) $153000(40000$ - 300000) /cumm

- Total cholesterol mg/dl(median (range)) $153(50-250)$

- Triglycerides mg/dl (median (range)) 146 (50-429)

- HDL cholesterol (median (range)) $34(8-49)$

Ultrasound

- Fatty liver (n(\%)) $23(79.3 \%)$

- Grade of fatty liver (median (range)) $2(0-3)$

- Chronic liver disease (n(\%)) $6(20.6 \%)$ 
diagnosed with fatty liver disease during the course of evaluation for persistently elevated transaminases (AST and/ or ALT). Pedal edema was the commonest manifestation amongst those with chronic liver disease. Of the rest $60.9 \%$ were asymptomatic. Fatigue was a complaint in $39.01 \%$ patients. Eight $(27.6 \%)$ patients had hypertension, of which 7 had a history of hypertension in the past and one was detected following enrolment in the study. Seven (24.13\%) patients had diabetes mellitus, of these four had history of diabetes mellitus, another three were diagnosed after enrolment in the study. One patient had ascites on presentation hence in this patient BMI and waist circumference was not calculated. In the remaining subjects the median BMI was $25.1(19.7-30.1) \mathrm{kg} /$ $\mathrm{m}^{2}$. Twenty four percent of patients had a BMI of $23-24.9 \mathrm{~kg} / \mathrm{m}^{2}$ and $51 \%$ of patients had a BMI of $\geq 25 \mathrm{~kg} / \mathrm{m}^{2}$. The median waist circumference was $95.25(63-110) \mathrm{cm}$. Central obesity was identified in $71.4 \%(\mathrm{n}=21)$ individuals.

\section{Histopathology}

Liver biopsy was performed in all the patients. Of the 23 patients without cirrhosis, more than 10 portal tracts were seen in 17 and five to ten portal tracts were seen in 6 biopsies. The predominant histological feature was steatosis. The steatosis was either predominantly macrovescicular, or mixed macro and microvescicular in type. Lobular inflammation was seen in all except three cases. The lobular inflammation consisted of mild infiltrates of lymphocytes, histiocytes and occasional neutrophils. On average $1-2$ foci of lobular inflammation was noted. Ballooning of hepatocytes was noted in 26 cases $(89.7 \%)$. Mallory's hyaline was noted in 9 cases $(31 \%)$, of which, in five it was not well formed. Seventeen (58.6\%) patients had evidence of fibrosis on liver biopsy which was of variable degree. Six had cirrhosis (Table 2).

\section{AST/ALT ratio and APRI}

ROC curves were constructed using AST/ALT ratio and APRI to differentiate between fibrosis grade $<2$ and more than $\geq 2$. For the AST/ALT ratio the area under the ROC (AUROC) was 0.9 (Figure 1). Using a cut off of $\geq 0.71$, the sensitivity and specificity for detection of advanced fibrosis was $81.8 \%$ and $72.2 \%$ respectively. For APRI the AUROCwas 0.68 (Figure 2). Using a cut off of $\geq 0.1$, the sensitivity and specificity for detection of advanced fibrosis was $72.7 \%$ and $72.2 \%$ respectively.
Table 2: Correlation of NAS scores and liver fibrosis.

\begin{tabular}{lcccc}
\hline $\begin{array}{l}\text { Fibrosis } \\
\text { score }\end{array}$ & \multicolumn{3}{c}{ (Non-Alcoholic steatohepatitis) } & Total \\
\hline $\mathbf{1}(<\mathbf{3})$ & $\mathbf{2 ( 3 - 4 )}$ & $\mathbf{3}(\mathbf{2} \mathbf{5})$ & Patients \\
\hline 0 & 2 & 6 & 4 & 12 \\
1a & 0 & 1 & 2 & 3 \\
$1 \mathrm{~b}$ & 0 & 0 & 0 & 0 \\
$1 \mathrm{c}$ & 0 & 0 & 3 & 3 \\
2 & 1 & 1 & 1 & 3 \\
3 & 0 & 2 & 0 & 2 \\
4 & 1 & 2 & 3 & 6 \\
\hline Total & 4 & 12 & 13 & 29 \\
\hline
\end{tabular}

ROC Curve

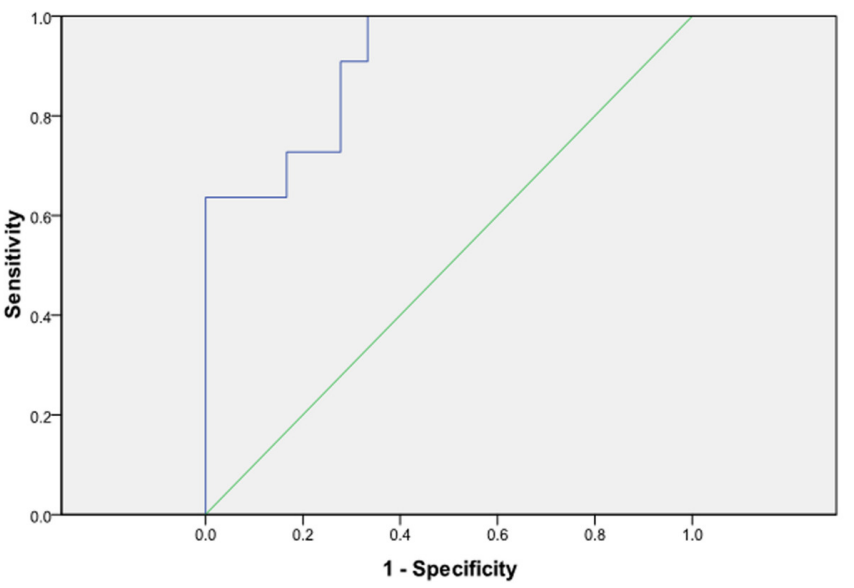

Figure 1:

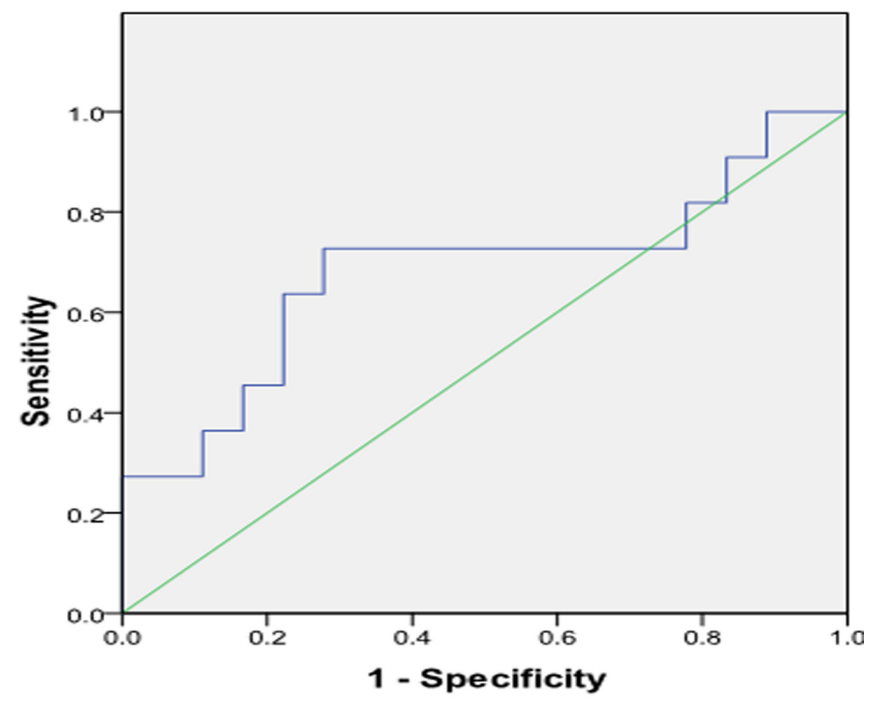

Figure 2:

\section{TNF alpha}

Of the 29 cases we were unable to amplify DNA in 4 samples for both -238 and -308 SNPs. The frequency distribution of the two polymorphisms is shown in Table $\mathbf{3}$ and shows that the vast majority of participants had the wild-type genotype, with 
Table 3: Distribution of frequency of TNF- $\alpha$ promoter polymorphisms $(n=25)$

\begin{tabular}{cccc}
\hline & GG & GA & AA \\
\hline-238 & $25(100 \%)$ & 0 & 0 \\
-308 & $22(88 \%)$ & $3(12 \%)$ & 0 \\
\hline
\end{tabular}

very few having an SNP. Presence of the SNPs was not correlated with the severity of fibrosis, although the numbers were too few to comment.

\section{Discussion}

In the present study, we evaluated the clinical profile, the liver histology, the role of non-invasive markers of liver fibrosis and the presence of polymorphisms in the TNF $\alpha$ promoter region in patients with NAFLD. Though NAFLD can affect people of any age, the prevalence of the disease seems to increase with age. ${ }^{24}$ The median age of diagnosis in our study was 43 (30 60) years. Other studies from India have also reported a similar age distribution. ${ }^{25,26}$ Though initial studies have shown a higher prevalence of the disease amongst women, ${ }^{27}$ two studies from India have also reported a higher prevalence of NAFLD amongst men. ${ }^{25,26}$ In the current study the majority of patients were male $(75.86 \%)$.

Many patients had an incidental detection of fatty liver and/or raised ALT either during workup for another illness, during planned organ donation, or during a medical check-up. Some patients $(39.01 \%)$ complained of fatigue. Most patients with NAFLD are asymptomatic although fatigue, malaise, and vague right upper abdominal discomfort bring some patients to medical attention. ${ }^{28}$ Fatigue in NAFLD is probably associated with autonomic dysfunction. ${ }^{29}$ Twenty four percent of patients were overweight and $51 \%$ were obese as per the criteria for obesity in Asians. ${ }^{15}$ Most studies have noted a high BMI in patients with NAFLD. ${ }^{30}$ Studies have also shown that central obesity is a correlate of visceral adiposity and is more closely linked to insulin resistance, the central event in NASH. ${ }^{31}$ Central obesity was noted in $71 \%$ of individuals with NAFLD.

Liver biopsy showed either predominantly macrovesicular or a mixed macro and microvesicular steatosis. Lobular inflammation was noted in all except 3 biopsies. A mixed lobular inflammation has been reported in NAFLD by Yeh et al. ${ }^{32}$ The most important diagnostic criterion for distinguishing steatohepatitis from simple steatosis is the presence of hepatocyte ballooning. ${ }^{33}$ Ballooning was noted in $96.5 \%$ patients. Thus, majority of our patients had steatohepatitis. Long-term follow-up studies show an increased liver related mortality in patients with steatohepatitis. ${ }^{34}$ Liver fibrosis appears to be one of the most important prognostic factors, as the presence of fibrosis suggests a more advanced and severe liver injury. ${ }^{35}$ Fibrosis was noted in $58.6 \%$ of our patients with NAFLD. This was notably higher than that reported by Madan et al. ${ }^{36}$ This could be due to the fact that we only studied patients who had been subjected to liver biopsy on clinical grounds, and did not biopsy all patients with suspected NAFLD.

We attempted to evaluate the utility of non-invasive tests (AST/ALT ratio and APRI) to predict the presence of significant fibrosis. AST/ALT ratio had a better diagnostic ability to identify advanced fibrosis (AUROC 0.9) as compared to the APRI (AUROC 0.68). Mcpherson et al also noted a higher diagnostic accuracy for AST/ALT ratio as compared to the APRI. ${ }^{37}$

This is the first study which looked at the presence of polymorphisms in the TNF alpha promoter region (-238,-308) in Indian patients with NAFLD. We did not find any difference in the allele frequency between the cases and controls for both loci. Studies have found a higher frequency of -238 polymorphisms in patients with NAFLD. ${ }^{13,38}$ A study done in Japan however did not find any difference in the allele frequency of TNF alpha promoter polymorphisms in patients with NAFLD. ${ }^{39}$ The limitation of this study was the low number of subjects included. Further studies involving more subjects need to be conducted, to evaluate the genetic influences on NAFLD amongst Indians.

In summary, AST/ALT ratio is an easy to calculate noninvasive test, obtained from simple laboratory parameters, which can identify advanced fibrosis. It may help us better identify the patients who might benefit the most from a liver biopsy.

\section{References}

1. de Alwis NMW, Day CP. Non-alcoholic fatty liver disease: the mist gradually clears. J Hepatol. 2008;48:S104-12.

2. GaidosJK, Hillner BE, Sanyal AJ. A decision analysis study of the value of a liver biopsy in nonalcoholic steatohepatitis. Liver Int. 2008;28:650-8.

3. Williams AL, Hoofnagle JH. Ratio of serum aspartate to alanine aminotransferase in chronic hepatitis. Relationship to cirrhosis. Gastroenterology. 1988;95:734-9.

4. Loaeza-del-Castillo A, Paz-Pineda F, Oviedo-Cárdenas E, Sánchez-Avila F, Vargas-Vorácková F. AST to platelet ratio index (APRI) for the noninvasive evaluation of liver fibrosis. Ann Hepatol. 2008;7:350-7.

5. Day CP, James OF. Steatohepatitis: a tale of two "hits"? Gastroenterology. 1998;114:842-5

6. Kugelmas M, Hill DB, Vivian B, Marsano L, McClain CJ. Cytokines and NASH: a pilot study of the effects of lifestyle 
modification and vitamin E. Hepatology.2003;38:413-9.

7. Carter-Kent C, Zein NN, Feldstein AE. Cytokines in the pathogenesis of fatty liver and disease progression to steatohepatitis: implications for treatment. Am J Gastroenterol. 2008;103:1036-42.

8. Wilson AG, di Giovine FS, Duff GW. Genetics of tumour necrosis factor-alpha in autoimmune, infectious, and neoplastic diseases. J Inflamm. 1995;45:1-12.

9. Wilson AG, di Giovine FS, Blakemore AI, Duff GW. Single base polymorphism in the human tumour necrosis factor alpha (TNF alpha) gene detectable by NcoI restriction of PCR product. Hum Mol Genet. 1992;1:353.

10. D'Alfonso S, Richiardi PM. A polymorphic variation in a putative regulation box of the TNFA promoter region. Immunogenetics. 1994;39:150-4.

11. Kroeger KM, Carville KS, Abraham LJ. The -308 tumor necrosis factor-alpha promoter polymorphism effects transcription. Mol Immunol. 1997;34:391-9.

12. Grove J, Daly AK, Bassendine MF, Day CP. Association of a tumor necrosis factor promoter polymorphism with susceptibility to alcoholic steatohepatitis. Hepatology. 1997;26:143-6.

13. Valenti L, Fracanzani AL, Dongiovanni P, Santorelli G, Branchi A, Taioli E, et al. Tumor necrosis factor alpha promoter polymorphisms and insulin resistance in nonalcoholic fatty liver disease. Gastroenterology.2002;122:274-80.

14. Chitturi S, Farrell GC, Hashimoto E, Saibara T, Lau GK, Sollano JD, et al. Non-alcoholic fattyliver disease in the Asia-Pacific region: definitions and overview of proposed guidelines. $J$ Gastroenterol Hepatol. 2007;22:778-87.

15. Redefiningobesity.pdf [Internet]. [cited 2012 Oct 3]. Available from: http://www.wpro.who.int/nutrition/documents/docs/ Redefiningobesity.pdf

16. Alberti KG, Zimmet P, Shaw J; IDF Epidemiology Task Force Consensus Group. The metabolic syndrome-a new world-wide definition. Lancet. 2005;366:1059-62.

17. The Seventh Report of the Joint National Committee on Prevention, Detection, Evaluation, and Treatment of High Blood Pressure. Bethesda (MD): National Heart, Lung, and Blood Institute (US); 2004.http://www.nhlbi.nih.gov/guidelines/ hypertension/jnc7full.pdf

18. Diagnosis and classification of diabetes mellitus.American Diabetes Association. Diabetes Care. 2010;33:S62-9.

19. Alberti KG, Zimmet P, Shaw J. Metabolic syndrome-a new world-wide definition. A Consensus Statement from the International Diabetes Federation. Diabet. Med. 2006;23:469-80.

20. Kleiner DE, Brunt EM, Van Natta M, Behling C, Contos MJ, Cummings OW, et al. Design and validation of a histological scoring system for nonalcoholic fatty liver disease. Hepatology. 2005;41:1313-21.

21. Adams LA, George J, Bugianesi E, Rossi E, De Boer WB, van der Poorten D, et al. Complex non-invasive fibrosis models are more accurate than simple models in non-alcoholic fatty liver disease. J Gastroenterol Hepatol. 2011;26:1536-43.

22. Wai CT, Greenson JK, Fontana RJ, Kalbfleisch JD, Marrero JA, Conjeevaram HS, et al. A simple noninvasive index can predict both significant fibrosis and cirrhosis in patients with chronic hepatitis C. Hepatology. 2003;38:518-26.

23. Gordon MA, Oppenheim E, Camp NJ, di Giovine FS, Duff GW, Gleeson D. Primary biliary cirrhosis shows association with genetic polymorphism of tumour necrosis factor alpha promoter region. J Hepatol. 1999;31:242-7.

24. Feldstein AE, Charatcharoenwitthaya P, Treeprasertsuk S, Benson JT, Enders FB, Angulo P. The natural history of nonalcoholic fatty liver disease in children: a follow-up study for up to 20 years. Gut. 2009;58:1538-44.

25. Amarapurkar D, Kamani P, Patel N, Gupte P, Kumar P, Agal S, et al. Prevalence of non-alcoholic fatty liver disease: population based study. Ann Hepatol. 2007;6:161-3.

26. Duseja A, Das A, Das R, Dhiman RK, Chawla Y, Bhansali A, et al. The clinicopathological profile of Indian patients with nonalcoholic fatty liver disease (NAFLD) is different from that in the West. Dig Dis Sci. 2007;52:2368-74.

27. Sheth SG, Gordon FD, Chopra S. Nonalcoholic steatohepatitis. Ann Intern Med. 1997;127:137-45.

28. Bacon BR, Farahvash MJ, Janney CG, Neuschwander-Tetri BA. Nonalcoholic steatohepatitis: an expanded clinical entity. Gastroenterology. 1994;107:1103-9.

29. Newton JL, Pairman J, Wilton K, Jones DE, Day C. Fatigue and autonomic dysfunction in non-alcoholic fatty liver disease. Clin Auton Res. 2009;19:319-26.

30. Bosserhoff A, Hellerbrand C. Obesity and fatty liver are "grease" for the machinery of hepatic fibrosis. Dig Dis. 2011;29:377-83.

31. Omagari K, Kadokawa Y, Masuda JI, Egawa I, Sawa T, Hazama $\mathrm{H}$, et al. Fatty liver in non-alcoholic non-overweight Japanese adults: incidence and clinical characteristics. J Gastroenterol Hepatol. 2002;17:1098-105.

32. Yeh MM, Brunt EM. Pathology of nonalcoholic fatty liver disease. Am JClin Pathol. 2007;128:837-47.

33. Hübscher SG. Histological assessment of non-alcoholic fatty liver disease. Histopathology. 2006;49:450-65.

34. Rafiq N, Bai C, Fang Y, Srishord M, McCullough A, Gramlich T, et al. Long-term follow-up of patients with nonalcoholic fatty liver. Clin Gastroenterol Hepatol. 2009;7:234-8.

35. Adams LA, Sanderson S, Lindor KD, Angulo P. The histological course of nonalcoholic fatty liver disease: a longitudinal study of 103 patients with sequential liver biopsies. J Hepatol. 2005;42:132-8.

36. Madan K, Batra Y, Gupta SD, Chander B, Rajan KD, Tewatia MS, et al. Non-alcoholic fatty liver disease may not be a severe disease at presentation among Asian Indians. World $J$ Gastroenterol. 2006;12:3400-5.

37. McPherson S, Stewart SF, Henderson E, Burt AD, Day CP. Simple non-invasive fibrosis scoring systems can reliably exclude advanced fibrosis in patients with non-alcoholic fatty liver disease. Gut. 2010;59:1265-9.

38. Hu ZW, Luo HB, Xu YM, Guo JW, Deng XL, Tong YW, et al. Tumor necrosis factor--alpha gene promoter polymorphisms in Chinese patients with nonalcoholic fatty liver diseases. Acta Gastroenterol Belg. 2009;72:215-21.

39. Tokushige K, Takakura M, Tsuchiya-Matsushita N, Taniai M, Hashimoto E, Shiratori K. Influence of TNF gene polymorphisms in Japanese patients with NASH and simple steatosis. J Hepatol. 2007;46:1104-10. 